\section{Presentación del Dossier \\ Lo jurídico, lo económico y lo político en el Hegel de la Filosofía del derecho}

\author{
Presentation of the Dossier \\ Legal, economic and political in Hegel's Philosophy of Right
}

Pablo Pulgar Moya; Héctor Ferreiro

Las Líneas fundamentales de la filosofía del derecho -conocida simplemente como Filosofía del derecho- se destaca como un texto todavía muy actual, pero también controversial. Desde su publicación en 1821 ha cosechado tanto loas como críticas en lo que respecta a sus tesis jurídicas, económicas y políticas. La importancia de esta obra descansa no solo en sus propuestas legales y normativas: se trata además de un tratado filosófico sobre temas tan fundamentales como la libertad, la sociedad civil y el Estado, entre muchos otros. Ya en la época de su publicación se venía vislumbrando una organicidad que ha sido interpretada como un programa sistemático del derecho que actualiza la idea de libertad, influyendo tanto en autores contemporáneos, como en autores posteriores. Si en Sobre las maneras de tratar científicamente el derecho natural (1802-1803) Hegel ensaya una superación de la doctrina del derecho natural, aun muy en boga en su época, es recién en la Filosofía del derecho donde considera programáticamente el despliegue y exposición del derecho en tanto expresión genética de cada uno de los momentos de la idea de libertad, la cual vuelve finalmente sobre sí -ya madura y reconciliada- en el Estado moderno. El Estado como organismo reconciliador de una sociedad civil en pugna (re)presenta una de las problemáticas más vivas y vivificantes; es el gozne no de individuos atomizados, sino de cada individuo en cuanto se hace a sí mismo miembro de la comunidad ética. El camino de la exposición da cuenta de la génesis de las instituciones públicas no menos que de la del propio individuo en cuanto persona, sujeto y miembro de comunidad. El congeniar entre sí voluntad individual, singular y universal supone ciertamente un desafío magnánimo de administración del poder mediante el derecho, pero ¿cómo comprender esa tarea sin antes tener en cuenta los pliegues del derecho mismo? Solo volviendo al ejercicio reflexivo en torno a las dimensiones del derecho deviene plausible una discusión sobre la composición orgánica de lo jurídico, de lo económico y de lo político al interior del conflicto social. Se torna así factible el pensar la libertad dentro del orden público y quehacer práctico, sea afirmativamente, sea críticamente. Las particularidades de la composición
INFORMACIÓN

http://doi.org/10.46652/resistances.v2i4.71 ISSN $2737-6222$

Vol. 2 No. 4, 2021, e21071

Quito, Ecuador

Enviado: diciembre 27, 2021

Aceptado: diciembre 29, 2021

Publicado: diciembre 31, 2021

Publicación continua

Sección dossier | Non Peer Reviewed

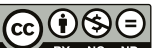

OPEN@ACCEss

AUTORES

Pablo Pulgar Moya

Universidad Católica Raúl Silva Henríquez - Chile

ppulgar@ucsh.cl

Héctor Ferreiro

Pontificia Universidad Católica Argentina Argentina

hferreiro@conicet.gov.ar

Conflicto de intereses

Los autores declaran que no existe conflicto de interés posible.

Financiamiento

No existió asistencia financiera de partes externas al presente artículo.

Agradecimiento

N/A

Nota

N/A
PUBLISHER

CICSSHYAL 
jurídica, la pertinencia de una integración económica resolutiva en forma de sistema de las necesidades [Bedürfnisse], la eclosión de una filosofía política reivindican de este modo el contenido racional aglutinante del derecho en su forma especulativa.

Con motivo del bicentenario de la publicación de las Líneas fundamentales de la filosofía del derecho hemos convocado tanto a investigadores emergentes como a investigadores formados y catedráticos para que desarrollen un análisis crítico de los distintos aspectos relevantes de la obra y su recepción en el pensamiento posterior. Entre los temas a los que los textos del dossier invitan al debate se cuentan, la tensión entre individuo y Estado, la teoría de la justicia, la pena y el castigo, la filosofía de la economía, la integración del fenómeno de lo político al interior del corpus hegeliano, el debate del concepto de moralidad en los jóvenes hegelianos, la violencia positiva del derecho y la función institucional del capital, entre otros. El objetivo general no es sino una reconstrucción sistemática del derecho, pero no como una mera correspondencia entre categoría y cosa, sino en cuanto descansa en la trama y subtrama de la propia libertad autodesplegada. La esperanza que nos mueve es que el dossier se convierta en un instrumento no solo para el debate entre especialistas en el pensamiento de Hegel, sino también para el diálogo interdisciplinario entre la filosofía y el derecho, la economía y la ciencia política.

Agradecemos a todas y todos los que han contribuido amablemente al número especial con un manuscrito de su autoría: María del Rosario Acosta (Riverside) Giulia Battistoni (Nápoles), Félix Duque (Madrid), Ana Miranda Mora (Ciudad de México/Berlín), Esteban Mizrahi (Buenos Aires), Angelo Narváez (Santiago de Chile), Sergio Pérez Cortés (Ciudad de México), Erzsébet Rózsa (Debrecen), Márcio Schäfer (Maranhâo), Friedrike Schick (Tübingen), Klaus Vieweg (Jena), a los cuales nos sumamos en calidad de editores y colaboradores. Queremos mencionar aquí también a quienes han ayudado en el proceso de corrección y traducción, sobre todo a Yared Elguera (Ciudad de México), Zaida Olvera (Cuernavaca) y Angelo Narváez. Finalmente queremos agradecer a los miembros del equipo editorial de Resistances. Journal of Philosophy of History, perteneciente al Centro de Investigaciones en Humanidades y Ciencias Sociales de América Latina (CICSHAL-RELIGACIÓN), quienes han confiado en nosotros como editores invitados del presente dossier para promover el estudio crítico del binomio Filosofía e Historia desde los diversos campos disciplinares.

\section{Editores Invitados}

Pablo Pulgar Moya. Universidad Católica Raúl Silva Henríquez, Chile/ Institut für kritische Theorie, Alemania-ppulgar@ucsh.cl

Héctor Ferreiro. Pontificia Universidad Católica Argentina/ Consejo Nacional de Investigaciones Científicas y Técnicas de Argentina - hferreiro@conicet.gov.ar

(Santiago de Chile/ Buenos Aires)

31 de diciembre de 2021 